\title{
Analysis on the Mobility of Urban Housing Price on Consumption in China
}

\author{
Huafu Shen, Shunbin Zhong \\ Department of Economics, \\ Central University of Finance and Economics \\ 39 South College Road Haidian District \\ Beijing,China
}

\begin{abstract}
This paper study the mobility of urban housing price on consumption in china's city. Firstly, this paper introduces the path of urban housing price on consumption. Secondly, the panel regression study shows that the increase of housing price has a significant positive effect on consumption. Further analysis by polynomial Logit shows that the rise of housing price has no significant impact on the location mobility of urban consumption from 2004 to 2008. In the period of 2008-2012, it can significantly promote the upward flow of urban consumption. In the cross-period from 2012 to 2016, it can significantly prevent the downward flow of urban consumption, while the upward flow has no significant impact. And these three different results are mainly due to the house price role in our economy.
\end{abstract}

Keywords: House price; Consumption; Mobility

\section{Introduction}

After the reform and opening up in China,especially since the 1990s, China's real estate market has developed rapidly and continuously, which has improved the housing conditions of tens of millions of families and strongly promoted economic and social development. However, with the passage of time, especially the stimulus policy of RMB 4 trillion at the end of 2008, a large amount of money poured into the real estate, and problems began to emerge. The housing prices in some first-tier cities and coastal cities soared, leaving the working class to feel helpless. The emergence of high housing prices prompts the prevalence of a large number of funds in the "de-real to virtual" to aggravate the bubble, at the same time, and to promote the impetuous social mentality. "Houses are for living, not for frying." General secretary Xi used such a simple sentence told the people. A meeting of the political bureau of the communist party of China central committee in July 2018 laid out six major tasks for the economy in the second half of the year, one of which was to resolve problems in the real estate market and specifically mentioned "resolutely curbing the rise in housing prices".

Apart from triggering people's living demand and influencing people's livelihood, the increase in housing prices is mainly concentrated in the consumption sector. Consumption is one of the three engines of economic growth. If housing prices have a significant impact on household consumption, it will not only affect people's livelihood and welfare, but also have an important impact on China's sustainable development. Therefore, whether the rise of housing prices will cause changes in consumption has attracted a lot of attention, such as: "the crowding out effect of high housing prices on household consumption is greater than the wealth effect?. As individuals, rising house prices clearly affect individual consumption. For the city, what is the impact of housing prices on consumption? Therefore, we will analyze empirically whether urban housing price can promote or reduce urban consumption, and whether the impact of housing price on consumption can also affect the mobility of consumption position.

\section{The relationship between urban housing price and consumption}

\subsection{The impact of urban housing price on urban consumption}

In general, the relationship between urban housing price and total retail sales of consumer goods ( referred to as Consumption ) mainly focuses on the impact of housing price rise on micro groups. However, on the medium level, taking the city as the object, is there a consistent trend between the two? Figure 1 below shows the relationship between housing price and total retail sales of consumer goods in cities in each period 


\section{Figure 1: Urban housing prices and total retail sales of consumer goods in China}

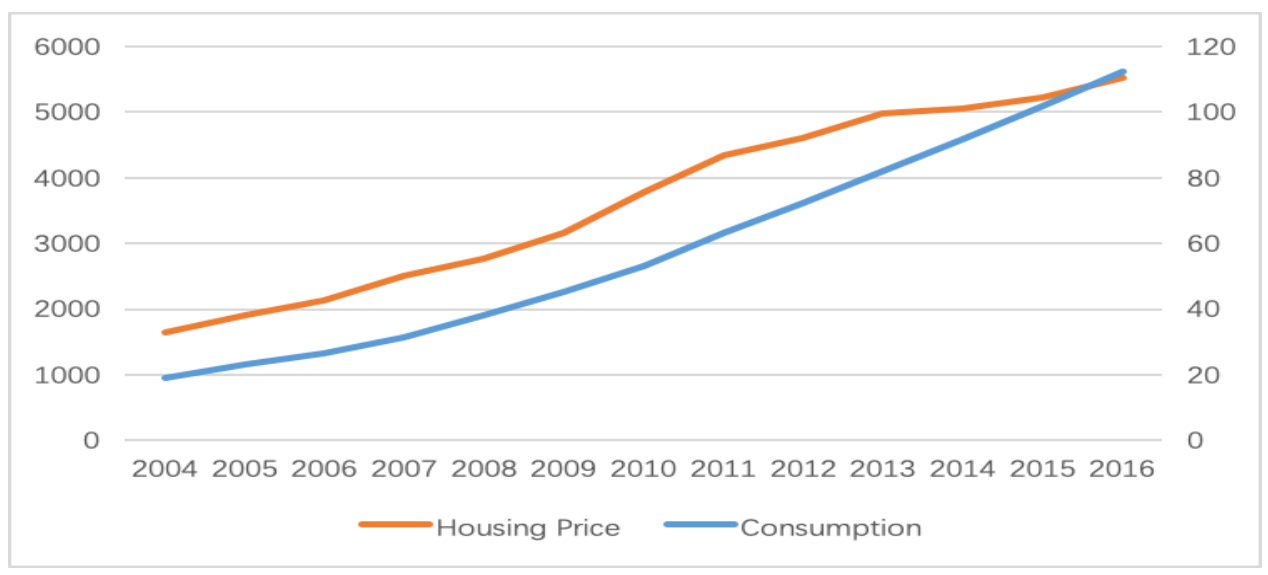

Sourch: CEIC Data ( Chinese Data )

Note: The left coordinate corresponds to the average housing price (yuan) in the city. On the right side is the average consumption of the city in tens of billions of dollars.

First, the housing price changes can be explained. According to the growth trend of the curve, the housing price changes can be divided into three periods. 2004-2008, 2008-2013, 2013-2016. Before 2008, the housing boom was a byproduct of the export boom. Especially after China's accession to the WTO, export has become the main driving force of China's economic growth. During this period, the rapid development of the real estate market was driven by the growth of economy and personal income. From 2008 to 2010, several opinions on promoting the healthy development of the real estate market issued by the state council on December 20, 2008, as well as several policies such as interest rate reduction and tax reduction, represented the central government's policy orientation of "stimulating the real estate market and stabilizing growth". From 2010 to 2013, after the target of stable growth was reached, the increase of housing price was significantly higher than that of residents' income, and governments at all levels began to strengthen regulation to curb the excessively rapid rise of housing price. After 2003, the green paper on housing: China's housing development report (2014-2015) held that in 2014, the housing investment and speculation tide completely disappeared, and the housing price in cities rose from the whole line to generally fell. The commodity housing enters the relative surplus stage, the turnover shrinks, the inventory level climbs. In 2015, the "330 New Deal" and the "930 New Deal" were introduced successively, and a combination of lowering down payment, reserve requirement, interest rate, tax and fee reduction, and shed renovation launched an unprecedented cycle of "raising prices and destocking". It was not until the "930" regulation policy was issued on the eve of National Day in 2016 that the central government set the spirit of "houses are used for living, not for speculation", and introduced policies of limited purchase, limited loan, limited sale, limited price and limited business. The change of housing price is closely related to policy and economic development obviously.

Secondly, we can be seen from the chart that, from 2004 to 2016, in this 12 years average house prices of the cities are between 1000 yuan and 6000 yuan respectively, and Consumption are from 2 billion to 12 billion. Each city average annual growth of about 332 yuan and 778 million yuan respectively and the average annual growth rate of about $10.6 \%$ and $15.9 \%$ respectively. The average annual growth rate of consumption significantly faster than prices. On the trend of the curve, the housing price and the consumption curve generally show a gentle upward trend, and the consumption is relatively more stable, but after 2013 , the housing price becomes more gentle, and the growth rate becomes smaller. There is a relationship between rising house prices and consumption clearly.

\subsection{The path of housing prices on consumption}

Investment, export and consumption are the troika driving economic growth. In previous years, it was always said that consumption was sluggish and the economy was always driven by investment, which was not healthy enough. There are many disadvantages of high housing price. The most intuitive one is that it may affect people's consumption ability and stimulate individuals to increase or restrain their consumption. Then how does the housing price affect the group's consumption? The following will be briefly elaborated from two aspects.

\subsubsection{Objects -- Different groups}

As everybody stands on different standpoint, so the relation of house price and consumption is different. 
From a micro point of view, for different groups of people whether they own a house or not, the effect of housing price rise on them is different ${ }^{1}$. Existing studies have basically confirmed the positive promoting relationship between household assets and household consumption (Tao et al, 2014). In the early stage ofhousing price rise, the wealth of property owners will increase with the housing price rise, and residents can also obtain positive returns through real estate investment ${ }^{2}$. At this time, the leverage ratio of the household sector is not high, and the increase in household income is faster than the increase in housing prices. In this context, the rising housing price will increase the marginal consumption tendency of residents and promote consumption growth, which is the wealth effect of the rising housing price. So for homeowners, a rise in house prices equals an increase in total assets, which boosts consumption; And for the homeless, different income groups are different. For households with houses, the "wealth effect" of high housing price on household consumption is significant. For those without houses or potential buyers, the high housing price has a negative "credit effect" on residents' consumption. For some middle - and low-income groups, housing purchase expenditure is the largest expenditure of the family. The rapid rise of housing price is bound to increase the pressure of rigid expenditure, and consumers will undoubtedly reduce other consumption expenditure, which has a squeezing effect on other consumption of residents. On the contrary, some people think that their income is not expected to increase as fast as the housing price, and they cannot afford to buy a house no matter how much they save. Why not increase consumption and improve their happiness, especially for some people who are considering buying a house or a car, which will promote the consumption of cars.For high earners, because their wages are rising faster than house prices, it is easier to think about saving to buy a house, no matter how high house prices rise, which will discourage consumption.More integrated information can be seen from Figure 2 below.

Figure 2 The impact of rising house prices on the consumption

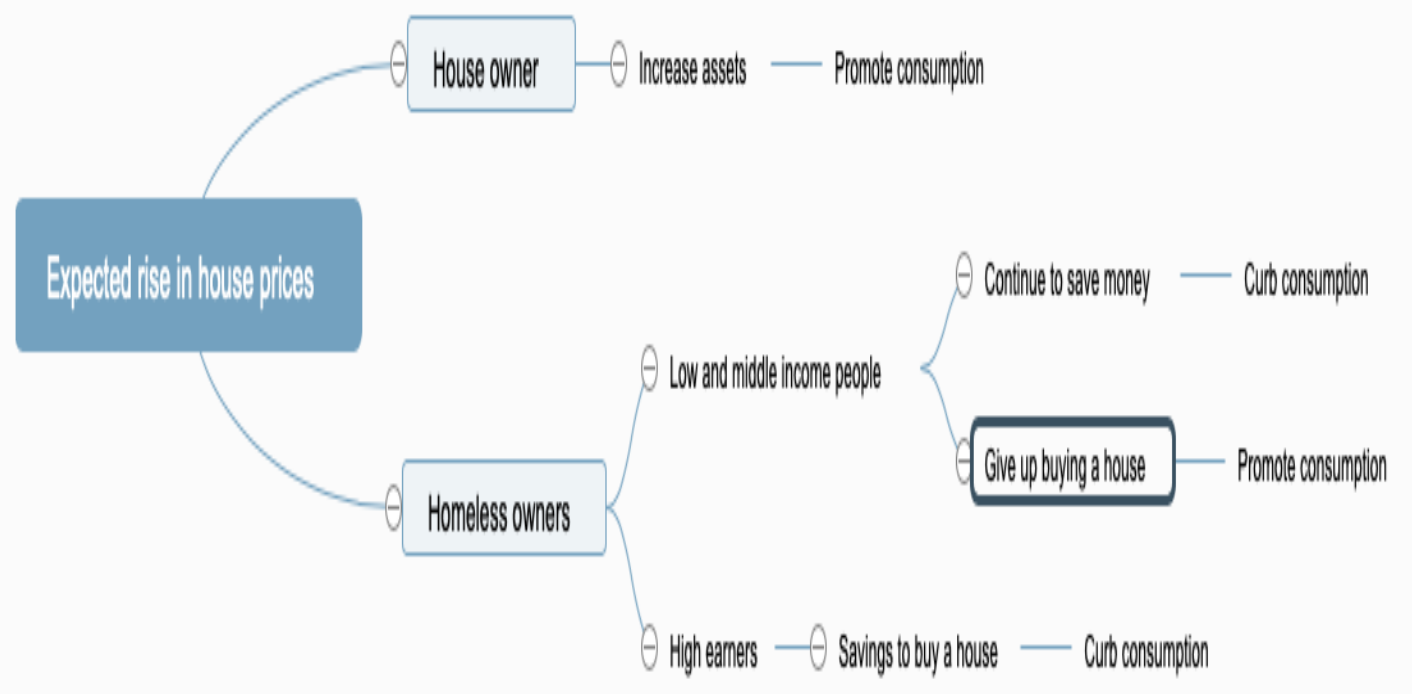

\subsubsection{Tool-Household leverage and down payment ratio}

First of all, the increase of residents' leverage ratio will increase the pressure of repaying loans, especially the rigid demand for housing, so that more disposable income will be used for repaying loans instead of daily consumption. Second, when house prices are pushed up by leverage, the down payment will be higher, so people will prefer to save, and thus consumption will be compressed, which is the performance of the double crowding out effect. Leverage drives home prices and increases payments and down payments. For example, as to owner of a house and the owner of no house, assuming that the monthly income of 10000, disposable income is 7000 , of which 5000 will be used to pay the mortgage, the remaining proportion of consumption can be small. And for the family that did not buy a house, it is the level that every month enters 10 thousand likewise, 7000 disposable income, as the rise of downpayment, majority person is inclined to save this money to buy a house, and won't go again wanton and profligate, consumption nature can be flagging.

\footnotetext{
${ }^{1}$ Zhou li (2018) believes that housing prices have different consumption behaviors for people without houses. For households with houses, the "wealth effect" of high housing price on household consumption is significant. For those without houses or potential buyers, the high housing price has a negative "credit effect" on residents' consumption.

${ }^{2}$ Huang jing et al. (2009) also believe that the rising wealth of real estate can promote the increase of consumption. 128
} 


\section{Panel analysis of urban housing prices on consumption}

There are different effects of urban housing price on the micro group. For the urban consumption at the medium level, whether the housing price will promote consumption is a comprehensive reaction of the micro behaviors of various groups in the city. Then, what will be the final impact of urban housing price on consumption over the years? We will answer through panel regression.

\subsection{Model and data description}

\subsubsection{The model}

According to the above analysis ideas, the following model can be constructed:

$C_{\text {it }}=\alpha_{1}+\alpha_{2} H P_{\text {it }+}+\beta_{j}^{\circ} X_{\text {it }+}+\varepsilon$

$\mathrm{C}$ represents the total retail sales of consumer goods in the city, HP represents the housing price in the city, and $\mathrm{X}$ is the control variable, including the population(Pop), per capita GDP of the city(Pgdp), residents' savings balance(Hsaving), actual use of foreign capital(Fdi), etc., all indicators have been adjusted. The selection of the above control variables mainly focuses on population, urban economy, finance and market openness. For cities, the main body of consumption is individual, so the population will directly affect the consumption; The per capita GDP of a city comprehensively reflects the strength of its economic development. When the urban economy develops rapidly, the consumption may also be high. There are two reasons for the selection of residents' savings balance as the control variable. First, it is generally believed that when residents' savings are high, their consumption will decrease, so consumption is related to savings. Second, it is also a financial indicator, reflecting the local financial investable ability. The actual use of foreign capital represents not only the degree of openness, but also the diversity of consumer goods. When the actual foreign capital is increased, the goods that need to be imported will be directly input into the domestic market, which will reduce the cost of shopping and increase the consumption.

\subsubsection{Data description}

According to the availability and absence of data, the time range of this chapter is from 2004 to 2016 . We will describe the major two variables.Statistical data of total retail sales of consumer goods and urban housing price are listed in Table 1 below. All data are adjusted to 2010.

Table 1 Data description of total consumer goods and housing prices

\begin{tabular}{|l|l|l|l|l|l|l|l|l|l|}
\hline & 2004 & \multicolumn{2}{l|}{2008} & \multicolumn{2}{l|}{2012} & \multicolumn{2}{l|}{2016} \\
\hline & Mean & Dev & Mean & Dev & Mean & Dev & Mean & Dev \\
\hline Total retail sales of consumer goods (100 million Yuan) & 212 & 574 & 486 & 1796 & 1076 & 3949 & 1330 & 4322 \\
\hline Housing Price(Yuan) & 1474 & 809 & 2097 & 1329 & 3208 & 1899 & 3891 & 3031 \\
\hline
\end{tabular}

Source:From the Chinese database of CEIC data and the statistical yearbook of Chinese cities.

According to the statistical results of four years' interval in table 1, both the total amount of consumer goods and the housing price are still on the rise after adjustment, and the growth rate before 2012 is larger, which is consistent with the large figure of China's economic growth. In terms of the difference between cities, the standard deviation of the total retail sales of social consumer goods is much higher than the average value, while the housing price is much lower. Therefore, it can be seen that the difference of the total retail sales of social consumer goods between cities is greater than the housing price. The total amount of retail sales of social consumer goods is often a reflection of the strength of a city's economic development. But the housing price is different, the housing price high and low by the commodity housing supply and demand decision, therefore both are not identical.

\subsection{Empirical analysis of the impact of urban housing price on consumption}

Analysis shows above that urban prices for individual and household consumption exist different effect. The city's total retail sales of social consumer goods is the sum of household consumption, it's different for each family effect have the effect of comprehensive. From the point of the city, city house prices on consumption of city is a what kind of effect, and different areas and whether performance is consistent, regular class city results? According to the above model, the following regression results can be obtained in this paper, as shown in table 2 below. 
Table 2 The result of housing price to consumption in all cities and four regions

\begin{tabular}{|l|l|l|l|l|l|l|l|}
\hline & $(1)$ & $(2)$ & East & Middle & West & North-east & ordinary -city $^{3}$ \\
\hline \multirow{3}{*}{ HP } & $0.336^{* * *}$ & $0.801^{* * *}$ & $0.314^{* * *}$ & -0.0154 & 0.016 & $0.116^{* * *}$ & $0.0458^{* * *}$ \\
\cline { 2 - 7 } & $(0.02)$ & $(0.02)$ & $(0.04)$ & $(0.02)$ & $(0.02)$ & $(0.03)$ & $(0.00759)$ \\
\hline \multirow{3}{*}{ Pop } & 0.0866 & & $7.290^{* * *}$ & $-0.815^{* * *}$ & $7.985^{* * *}$ & $20.08^{* * *}$ & 0.13 \\
\cline { 2 - 7 } & $(0.17)$ & & $(2.35)$ & $(0.30)$ & $(0.65)$ & $(2.39)$ & $(0.261)$ \\
\hline \multirow{2}{*}{ Pgdp } & -0.0078 & & 0.0227 & $0.0235^{* * *}$ & -0.00431 & 0.00456 & $0.00484^{*}$ \\
\cline { 2 - 7 } & $(0.01)$ & & $(0.02)$ & $(0.01)$ & $(0.01)$ & $(0.01)$ & $(0.00274)$ \\
\hline \multirow{3}{*}{ Hsaving } & $0.000117^{* * *}$ & & $6.35 \mathrm{e}-05^{* * *}$ & $3.29 \mathrm{e}-05^{* * *}$ & $4.31 \mathrm{e}-05^{* * *}$ & $3.01 \mathrm{e}-05^{* * *}$ & $0^{* * *}$ \\
\cline { 2 - 8 } & $(0.00)$ & & $(0.00)$ & $(0.00)$ & $(0.00)$ & $(0.00)$ & $(1.91 \mathrm{E}-06)$ \\
\hline \multirow{3}{*}{ Fdi } & $5.18 \mathrm{E}-05$ & & $0.0148^{* * *}$ & $0.00754^{* * *}$ & $1.80 \mathrm{e}-05^{* * *}$ & $0.000676^{* * *}$ & $0.00157^{* * *}$ \\
\cline { 2 - 7 } & $(0.00)$ & & $(0.00)$ & $(0.00)$ & $(0.00)$ & $(0.00)$ & $(0.000252)$ \\
\hline \multirow{2}{*}{ Constant } & $-1,133^{* * *}$ & $-1,382^{* * *}$ & $-5,888^{* * *}$ & 189.9 & $-3,118^{* * *}$ & $-6,372^{* * *}$ & $-247.9^{* *}$ \\
\cline { 2 - 7 } & $(108.20)$ & $(121.80)$ & $(1146.00)$ & $(136.80)$ & $(246.50)$ & $(741.10)$ & $(101.8)$ \\
\hline \multirow{2}{*}{ Sample size } & 282 & 286 & 87 & 80 & 81 & 34 & 249 \\
\hline
\end{tabular}

Note:(1) is the result based on the whole sample and each control variable.(2) it is only the regression result of housing price and consumption. The eastern ${ }^{4}$ part is the regression under the condition of taking the eastern cities as samples. The other three regions and ordinary cities are similar to Eastern part city.Standard errors in parentheses , *** $\mathrm{p}<0.01$, $* * \mathrm{p}<0.05, * \mathrm{p}<0.1$.

Based on the results of Hausman test, the random effect model is selected in this paper. Table 2 reports the random effect regression results based on the model. The full sample (1) shows that the rise of urban housing price has a positive effect on the total retail sales of urban consumer goods. In order to illustrate the robustness of the results, only the regression results of the two are made, as shown in the full sample (2), which indicates that the results are robust to some extent. If the results are applied to the micro level, it can be seen that for urban residents, high housing prices show more "wealth effect". That is, "wealth effect" is greater than "credit effect". Zhou et al. (2018) concluded from micro data that there is a significant positive "wealth effect" of housing in Chinese cities, that is, housing price rise promotes residents' consumption, and our results are consistent with it. This also indicates that more people in the micro group own houses and show a strong wealth effect.

The rest of the five major categories based on (1) the regression results for the model。By contrast, we found the eastern and northeastern cities in the four regions show with consistent is significant impact on the whole samples. The persistent rising housing prices in the central and western cities had no significant effect on consumption, which is not completely consistent with the full sample. The average per capita GDP ratio of the four major regional cities is: 9066:5540:5469:7622, which indicates that the continuous rise of housing prices can only promote the increase of urban consumption in regions with better economic development. Generally, it is believed that the marginal consumption tendency of urban groups in the regions with better economic development is larger, and the risk preference is stronger. Therefore, when the housing price rises, the household wealth increases. Due to the marginal tendency and risk preference, Urban populations in areas with better economic development will translate more of the "invisible" increase in wealth into consumption, which will boost consumption significantly. However, due to strong risk aversion in cities with weak economic development, they will not increase consumption too much even if the family wealth increases. As a result, the continuous rise of housing price has no obvious effect on consumption. Further weconstruct a common city class samples and regression analysis also showed that house prices continue to rise significantly promote urban consumption increase, this is consistent with the total sample results, it shows that the influence of city house prices on consumption analysis on the common class of above of city and vice provincial cities both have the separable and combined nature combined, but not for the four regions.

\footnotetext{
${ }^{3}$ Ordinary cities refer to ordinary prefecture-level cities of departmental administrative units, that is, cities at the sub-provincial level, cities listed separately in the plan and municipalities directly under the central government are excluded. The regression results of non-ordinary cities are also positive and significant, and the results are not given in the table.

${ }^{4}$ In China, city locates in different region. According to different geographical locations, the city is divided into four regions: east, central, west and northeast part. 


\section{Empirical mobility analysis of urban housing price on consumption}

The global financial crisis that broke out in 2008 and the sino-us trade conflict in 2018 have shown that if we only rely on exports, it will cause great pressure on China's economic growth. Therefore, expanding economic "domestic demand" is the best choice, so it is more important to promote household consumption. From the micro level to the medium city level, the increase of household consumption will increase the urban consumption. The change of urban consumption amount in a period reflects the effect of "expanding domestic demand" of cities in that period. When the increase of urban consumption varies in different periods, urban consumption flows in different periods. Some cities are growing more and they may stay at higher levels, and some are growing less and they may lay at lower levels. As we know, factors that can affect consumption may also affect the positional mobility of consumption. However, in recent years, the sharp rise of urban housing prices, more triggered people's attention to consumption. The rising urban housing price promotes the increase of urban consumption, so will the rising housing price also have an impact on the mobility of consumption?

\subsection{Model and Data description and Transformation matrix of consumption}

\subsubsection{Model and Data description}

\section{(1)The model}

According to the above analysis ideas, the following model can be constructed:

mobility_c $=\alpha_{1}+\alpha_{2}$ plocation $+\alpha_{3} h p_{-} c h+\beta_{j} \Delta X+\varepsilon$

Where mobility_c represents the mobility of consumption, the upward mobility is denoted as "1", the downward mobility is "-1", and the fixed mobility is "0". Also, plocationn represents the initial position, $h p_{-}$ch is a change in price, delta $\Delta X$ represents a variable control variable._ch represents the change. For example, Pgdp_chrepresents the change in the beginning and end year.

\section{(2) Data description}

The time selected in this chapter is still in accordance with the above section. The period from 2004 to 2016 is divided into four years, which is mainly due to two reasons. First, before 2002, house price data from the "the statistical yearbook of Chinese cities" were missing. Secondly, since 2004, it is mainly cover the complete span period. The data description of consumption, housing price and per capita GDP are described in the Table 3 below.

Table 3 Intertemporal statistical description of urban consumption and housing prices

\begin{tabular}{|c|c|c|c|c|c|c|c|c|c|c|c|c|}
\hline & \multicolumn{4}{|c|}{ 2004-2008 } & \multicolumn{4}{|c|}{$2008-2012$} & \multicolumn{4}{|c|}{$2012-2016$} \\
\hline & Mean & Dev & Max & Min & Mean & Dev & Max & Min & Mean & Dev & Max & Min \\
\hline $\begin{array}{l}\text { Consumption(100 } \\
\text { million Yuan) }\end{array}$ & 382 & 1574 & 15874 & -895 & 709 & 2102 & 19871 & -519 & 382 & 1438 & 15723 & $\begin{array}{l}- \\
2227\end{array}$ \\
\hline Housing Price(Yuan) & 724 & 750 & 5193 & -584 & 1165 & 777 & 5900 & 116 & 765 & 1614 & 18650 & $\begin{array}{l}- \\
2984\end{array}$ \\
\hline Pgdp(Yuan) & 786 & 1571 & 9036 & $\begin{array}{l}- \\
9662\end{array}$ & 495 & 1268 & 4365 & $\begin{array}{l}- \\
8020\end{array}$ & -534 & 1218 & 3415 & $\begin{array}{l}- \\
7569\end{array}$ \\
\hline
\end{tabular}

As can be seen from the inter-temporal description in table 5.3 above, urban consumption increased the most from 2008 to 2012, and the inter-temporal consumption of the other two years was just the same, where the former was 1.85 times of the latter. In terms of the largest growth, it also occurred in the inter-period of 2008-2012, while the smallest growth occurred in the period of 2012-2016. Therefore, although consumption is growing, the inter-temporal comparison shows that the consumption growth in 2012-2016 is the worst. In terms of housing price, it also shows that the two inter-temporal average housing price is close to each other. During 2008-2012, the average housing price of the cities grew the fastest, about 1.6 times as much as that of the other two periods. However, the difference between 2012-2016 is the largest, and the housing price of the cities fluctuates greatly, which means that there is the largest housing price increase and the largest housing price decline. On the other hand, the average per capita GDP of cities decreased and even showed negative growth from 2012 to 2016. Over the past 12 years, the city's per capita GDP has not maintained a sustained growth.

\subsubsection{Transformation matrix of consumption}

In addition to the sample description, we also made a 10 -fold transformation matrix for consumption in three periods and reported the mobility indicators of upward, original and downward. The results are shown in table 4 below. 
Table 4 The flow ratio and liquidity index in the consumption transformation matrix

\begin{tabular}{|l|l|l|l|l|l|}
\hline & -1 & 0 & 1 & Mq $^{3}$ & MP \\
\hline $2004-2008$ & $20.4 \%$ & $49 \%$ & $30.6 \%$ & More than 1 & 0.567 \\
\hline $2008-2012$ & $22.7 \%$ & $49.6 \%$ & $27.6 \%$ & More than 1 & 0.56 \\
\hline $2012-2016$ & $21.6 \%$ & $51.4 \%$ & $27 \%$ & More than 1 & 0.54 \\
\hline
\end{tabular}

It can be seen from table 4 that, first of all, although the proportion of urban consumption in the original position is still large, around 50\%, from the consumption ratio of upward and downward cities, the consumption mobility quality in the three periods is greater than 1, and the overall mobility trend become better. Secondly, the mobility of urban consumption was the strongest in 2004-2008, close to that in 2008-2012 and the weakest in 2012-2016. The mobility of urban consumption is mainly reflected in the number of cities that remain in the original position. From 2004 to 2008, there were $49 \%$ of cities. From 2012 to 2016, there were more than half of cities. In a word, during the three periods, the ratio of solidified cities was increasing, and the mobility was decreasing, and the upward mobility of cities was decreasing.

Further analysis of the cities with different levels in the original position shows that (Figure 3 below), compared with the urban consumption in other two periods, the proportion of 8 classes remaining in the original position in 2012-2016 is higher. For example, the class 1-3 and 6-10 accounting for 80\%. Similarly, compared with the other two periods(2004-2008,2008-2012), in the urban consumption growth in the last four years, the cities with rapid growth and the cities with slow growth still maintain the growth trend of rapid and slow respectively, and only the cities with the growth in the middle class are relatively less solidified. In 2004-2008, the mobilityis the strongest, the fluctuation was relatively small in all levels and the overall trend was relatively average. From 2008 to 2012, the best mobilityoccurs in the class 8 and the worse inthe class 10. It can be seen that the liquidity of urban consumption growth in 2008 to 2012 was highly volatile in terms of the mobility of each class and the degree of solidification was small.

Figure 3 Diagonal diagram of three period transition matrix

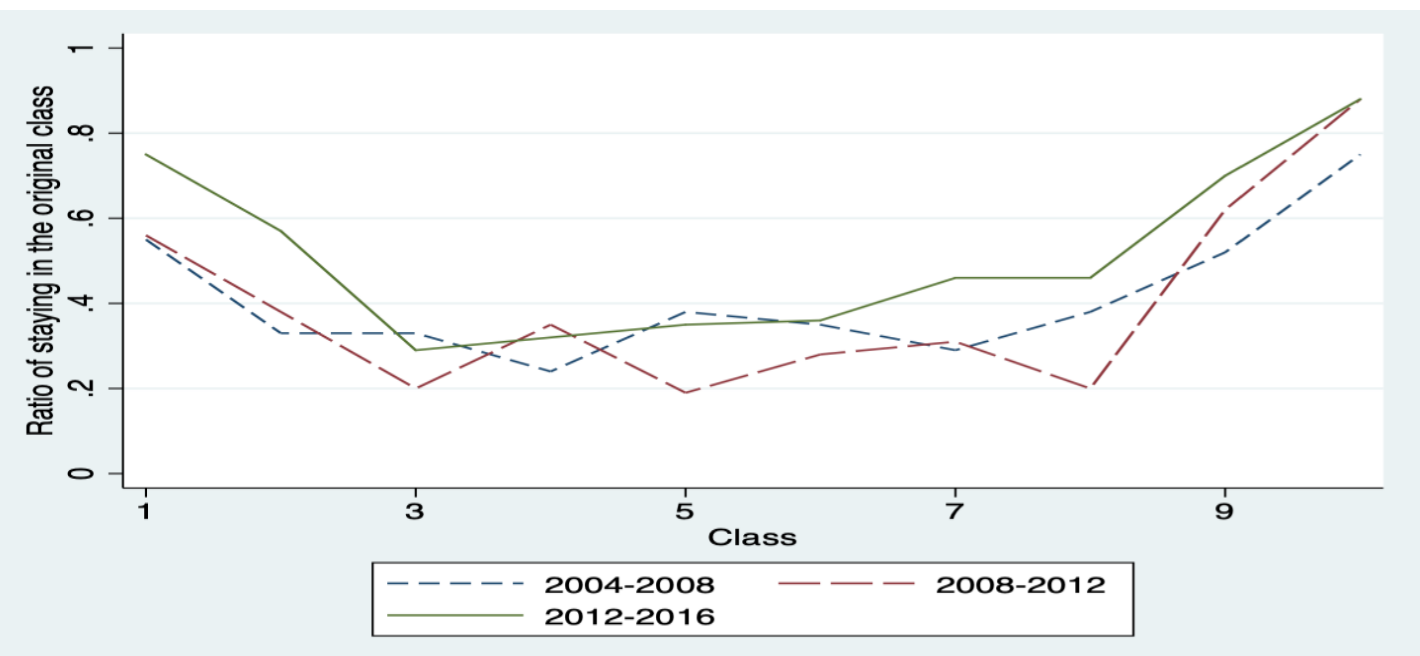

Source:Transformation matrix of three periods.

\subsection{Polynomial Logit analysis of urban housing price to consumption}

According to the existing data and polynomial Logit model, the regression results of three different periods are summarized in the following Table 5.

${ }^{5} \mathrm{Mqrepresents} \mathrm{the} \mathrm{quality} \mathrm{of} \mathrm{mobility.} \mathrm{If} \mathrm{the} \mathrm{Mq} \mathrm{is} \mathrm{greater} \mathrm{than} \mathrm{1,} \mathrm{which} \mathrm{shows} \mathrm{the} \mathrm{mobility} \mathrm{becomes}$

better. $M p=\frac{n-t r a c e(p)}{n-1}($ Shorrocks, 1978). Greater Mp indicates greater mobility. 
Table 5 The polynomial regression result of housing price on consumption

\begin{tabular}{|l|l|l|l|l|l|l|}
\hline & $2004-2008$ & \multicolumn{7}{l}{$2008-2012$} & \multicolumn{2}{l|}{$2012-2016$} \\
\hline & -1 & 1 & -1 & 1 & -1 & 1 \\
\hline \multirow{3}{*}{ plocation } & $0.206^{* *}$ & -0.0562 & $0.434^{* * *}$ & -0.0395 & $0.310^{* * *}$ & $-0.137^{*}$ \\
\cline { 2 - 7 } & $0.09)$ & $(0.08)$ & $(0.10)$ & $(0.09)$ & $(0.10)$ & $(0.08)$ \\
\hline \multirow{3}{*}{ Hp_ch } & 0.0002 & -0.000167 & 0.000241 & $0.000515^{*}$ & $-0.000594^{* *}$ & -0.000162 \\
\cline { 2 - 7 } & $(0.00)$ & $(0.00)$ & $(0.00)$ & $(0.00)$ & $(0.00)$ & $(0.00)$ \\
\hline \multirow{3}{*}{ Pgdp_ch } & $-4.35 \mathrm{E}-05$ & $3.52 \mathrm{E}-05$ & -0.000173 & $0.000318^{*}$ & -0.000111 & $0.000747^{* * *}$ \\
\cline { 2 - 7 } & $(0.00)$ & $(0.00)$ & $(0.00)$ & $(0.00)$ & $(0.00)$ & $(0.00)$ \\
\hline \multirow{3}{*}{ Pop_ch } & -59.97 & -66.84 & 32.68 & 79.1 & -112.5 & 1.139 \\
\cline { 2 - 7 } & $(120.70)$ & $(118.60)$ & $(71.29)$ & $(51.25)$ & $(70.43)$ & $(56.25)$ \\
\hline \multirow{4}{*}{ Fdi_ch } & -0.0554 & 0.0504 & -0.101 & -0.0317 & -0.0544 & $-0.0657^{*}$ \\
\cline { 2 - 7 } & $(0.07)$ & $(0.05)$ & $(0.08)$ & $(0.06)$ & $(0.03)$ & $(0.04)$ \\
\hline \multirow{3}{*}{ Hsaving_ch } & $-3.59 \mathrm{e}-07^{* * *}$ & $-1.28 \mathrm{E}-07$ & $-6.31 \mathrm{e}-07^{* * *}$ & $-2.13 \mathrm{e}-07^{*}$ & $-2.73 \mathrm{e}-07^{* *}$ & $1.63 \mathrm{E}-09$ \\
\cline { 2 - 7 } & $(0.00)$ & $(0.00)$ & $(0.00)$ & $(0.00)$ & $(0.00)$ & $(0.00)$ \\
\hline \multirow{2}{*}{ Constant } & -0.701 & 0.397 & -0.549 & -0.207 & $-1.382^{* * *}$ & 0.457 \\
\cline { 2 - 7 } & $(0.47)$ & $(0.41)$ & $(0.47)$ & $(0.42)$ & $(0.49)$ & $(0.34)$ \\
\hline
\end{tabular}

Standard errors in parentheses, $* * * \mathrm{p}<0.01, * * \mathrm{p}<0.05, * \mathrm{p}<0.1$

As can be seen from table 5, during the inter-period from 2004 to 2008, the rise of housing price had no significant influence on the location mobility of urban consumption. As we know from 2002 to 2007, the real estate market was mainly controlled by policies, and the real estate industry never became a policy tool for stable growth. At this time, although the housing price rose rapidly, it was not completely divorced from the income level of residents, and there was hardly any bubble in the housing price. In 2004-2008, even though housing price can promote consumption, this influence is limited and cannot make urban consumption have obvious cross-class mobility. From 2008 to 2012, the rise of housing price can significantly promote the upward flow of urban consumption, which is also related to the impact of real estate on China's economy. From 2008 to 2013, China's real estate led the economic growth cycle. Therefore, during the period from 2008 to 2012, the housing price continued to rise, the wealth of the group with a house increased significantly, and the consumption ability increased significantly, leading to upward mobility of urban consumption.

In the cross-period from 2012 to 2016, the increase of housing price can significantly prevent the downward flow of urban consumption, while the upward flow has no significant impact. Similarly, the influence of housing price on consumption position flow is also the result of the country's real estate regulation and control finally affecting consumption. As a result, under a series of measures by the state, the growth of housing prices has slowed down. More figuratively, Assuming that if the housing price rise is not curbed in 2012-2016, the consumption that influences the significant upward flow of the city will be assumed to increase from 1000 to 15000 , while the consumption that influences the downward flow will increase from 1000 to 10100 (including the downward flow that decreases actively and the "passive" flow that increases less). When the real estate regulation occurs, the expected future wealth value will decrease and the current consumption will also decrease, so the housing price will increase the upward flow of consumption from 1000 to 10200 . At this time, the housing price will have a very small impact on the upward flow of consumption, and there is no significant causal relationship. Due to less consumption decrease in downward flowing cities, the impact of housing price increases many increase from 1000 to 10080. In contrast, the decrease of downward flowing consumption is less, which is equivalent to a much larger "net" increase. Therefore, housing can prevent downward flow. In addition, it is particularly important to note the influence of other control variables on class mobility, especially the increment of urban per capita GDP and resident savings balance. The effect of the former on consumption liquidity is only in the latter two periods, and only has a significant impact on upward flow, the rest of the case has no significant impact. This suggests that cities with high GDP per capita do not necessarily promote upward consumption flows and discourage downward consumption flows. The change in the resident savings balance can significantly prevent the downward flow of urban consumption. The more urban residents' savings increase, it prevents consumption from flowing downward

\section{Conclusion}

The impact of China's urban housing price on urban consumption is an important issue of urban economic growth and mobility. It is also a hot topic today and even in the next decade. 
It is not only the impact of housing price on people's livelihood, but also the impact of housing price on residents' consumption and welfare, and even the impact of urban consumption. Therefore, this paper discusses the impact of housing price on consumption from three aspects. First, the relationship between housing prices and consumption mainly focuses on two aspects. First of all, this paper expounds the trend relationship between the two in terms of time from data, and describes the role of three different housing prices in the national economy. Secondly, it analyzes the influence path of housing price on consumption, mainly from the micro consumer groups and means. In general, housing price has wealth effect and crowding out effect on the group. When the wealth effect is larger than the crowding out effect, housing price can promote the increase of consumption, and vice versa. Of course, for the owner of a house, the effect is different. In terms of means, residents' disposable income can be adjusted mainly through their leverage ratio and different down payment ratio, thus affecting consumption.

Second, through panel regression analysis, high housing prices are more likely to show the "wealth effect" for urban residents. The "wealth effect" is greater than the "credit effect", which proves that the continuous rise of housing prices will promote the increase of urban consumption. In the four regions, only the eastern and northeastern cities showed positive and significant effects consistent with the whole sample, while the continuous increase of housing price in the central and western cities had no significant effects on consumption, which was not completely consistent with the regression results taking the whole city as the sample. In the regions with better economic development, the marginal tendency of group consumption is larger and the risk preference is stronger. The continuous rise of housing price can only promote the increase of urban consumption in areas with better economic development. Finally, on the basis of consumption class mobility, Mlogit model is used to analyze whether housing price has an impact on mobility. In the three inter-phase, it is found in the transformation matrix that the urban consumption more from 2004 to 2008 is the strongest, that from 2008 to 2012 is relatively close, and that from 2012 to 2016 is the weakest. The regression results show that in the inter-period from 2004 to 2008, the rise of housing price has no significant impact on the location mobility of urban consumption. In the period of 2008-2012, the increase of housing price can significantly promote the upward flow of urban consumption. In the cross-period from 2012 to 2016, the increase of housing price can significantly prevent the downward flow of urban consumption, while the upward flow has no significant impact. And these three different results are mainly due to the house price role in our economy.

\section{Reference}

HuaDongZ,Linlin G. China's housing "wealth effect" mystery - inspection based on China's housing system reform[J].China Economic Studies,2018[7].

Jing H,Mei C T. Real estate wealth and consumption: evidence from household micro survey data[J]. Management World,2009[7].

Kerm P V. What Lies Behind Income Mobility? Reranking and Distributional Change in Belgium, Western Germany and the USA[J]. Economica, 2004, 71(282):223-239.

Li Z. High housing prices, balance sheet effect and urban consumption[J].Economic Science,2018(6).

Shorrocks A F. The Measurement of Mobility[J]. Econometrica, 1978, 46(5):1013-1024.

Tao L,Binkai C. Family, the wealth effect and the residents' consumption of fixed assets: empirical evidence from China's urban families[J].Economic Research,2014(3). 